\title{
Hydrogen bond radii for the hydrogen halides and van der Waals radius of hydrogen
}

\author{
Pankaj K. Mandal and E. Arunan ${ }^{\text {a) }}$ \\ Department of Inorganic and Physical Chemistry, Indian Institute of Science, Bangalore, India 560012
}

\begin{abstract}
In this article, the effective size of hydrogen in the hydrogen halides forming hydrogen bonded complexes is estimated. The scheme proposed by Bhadane and Gadre [J. Chem. Phys. 107, 5625 (1997)] for estimating the size of hydrogen in HF is extended to the other hydrogen halides ( $\mathrm{HCl}$ and $\mathrm{HBr}$ ) and $\mathrm{HCN}$. It is noted that the radius of $\mathrm{H}$ atom in $\mathrm{HF}, \mathrm{HCl}, \mathrm{HBr}$, and $\mathrm{HCN}$ are, respectively, $0.55 \pm 0.07,0.74 \pm 0.08,0.80 \pm 0.11$, and $0.93 \pm 0.07 \AA$. The radii found for $\mathrm{HF}, \mathrm{HCl}$, and $\mathrm{HBr}$ show a strong inverse correlation with the dipole moment of the HX. From this correlation the radius of $\mathrm{H}$ atom in $\mathrm{HI}$ is estimated to be $0.90 \pm 0.11 \AA$. By extrapolating to zero dipole moment, the van der Waals radius of $\mathrm{H}$ atom is determined to be $1.0 \pm 0.1 \AA$, reasonably close to the value proposed by Pauling, $1.2 \AA$.
\end{abstract}

The nature of chemical bonding, the interaction between atoms within a molecule, is fairly well understood. ${ }^{1}$ Pauling's classic book ${ }^{1}$ talks about covalent radii, ionic radii, and metallic radii for various atoms which can be used to predict interatomic distances between atoms forming a covalent, ionic or metallic bond. ${ }^{1}$ However, our understanding of intermolecular interactions is still evolving. ${ }^{2}$ In the last three decades, extensive studies on weakly bound complexes have been reported that address intermolecular interaction directly. ${ }^{3}$ These complexes are largely classified as van der Waals or hydrogen bonded complexes. The intermolecular separations in these complexes have been largely interpreted in terms of the van der Waals radii ${ }^{1}$ of the constituent atoms. For hydrogen bonded complexes B-HF, Buckingham and Fowler ${ }^{4}$ have shown that the $\mathrm{Z}-\mathrm{F}(\mathrm{Z}$ is the atom in $\mathrm{B}$ that is $\mathrm{H}$ bonded to HF) distance is within $0.1 \AA$ of the sum of van der Waals radii of $\mathrm{Z}$ and $\mathrm{F}$. However, for $\mathrm{B}-\mathrm{HCl}$ and $\mathrm{B}-\mathrm{HBr}$, the $\mathrm{Z}-\mathrm{X}$ distances are, for several complexes, $0.2 \AA$ or more larger than the sum of van der Waals radii for $\mathrm{Z}$ and $\mathrm{X}^{5}$

Gadre and Bhadane ${ }^{6}$ analyzed the $\mathrm{Z}-\mathrm{H}$ distances in about 20 complexes formed by HF. They computed the molecular electrostatic potential (MESP) for the free bases B at the SCF and MP2 levels with 6-31++G(**) basis set. They noted that the MESP minimum symbolize the site of electron localization in a molecule which attracts hydrogen. The location of the MESP minima could explain the radial and angular geometry of the B-HF complexes. Gadre and Bhadane further noted that the following correlation existed between $r_{\mathrm{Hyd}}$ and $r_{\mathrm{ESP}}$, which are defined below,

$$
r_{\mathrm{Hyd}}=\left(r_{\mathrm{ESP}} \times 1.04\right)+0.47 \text {. }
$$

Here, $r_{\mathrm{Hyd}}$ is the $\mathrm{Z}-\mathrm{H}$ distance in the complex, where $\mathrm{Z}$ is the atom or center in $\mathrm{B}$, which is bonded to the $\mathrm{H}$ and $r_{\mathrm{ESP}}$ is the distance between $\mathrm{Z}$ and the MESP minimum. The results obtained with HF and MP2 methods were very similar. It

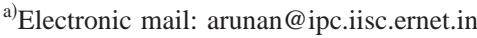

was pointed out that the $r_{\text {ESP }}$ was closer to the van der Waals radius of the $\mathrm{Z}$ atom. Hence, they concluded that $0.47 \AA$ is the van der Waals radius of $\mathrm{H}$. It is significantly smaller than the value suggested by Pauling $(1.2 \AA)$ and this feature has been noted in the literature. ${ }^{4}$ The difference is not surprising given the fact that $\mathrm{H}$ bonding (electrostatic) interactions are significantly stronger than van der Waals (induction and dispersion) interactions. It should be pointed out that the effective radius of $0.47 \AA$ for $\mathrm{H}$ in $\mathrm{HF}$ is larger than the covalent radius of the $\mathrm{H}$ atom, $0.3 \AA{ }^{1}$

In this paper, we extend the Gadre and Bhadane analysis to the other hydrogen halides. Over the last few years precise structural data have become available for several B-HX complexes which has encouraged this study. Table I lists the $\mathrm{Z}-\mathrm{H}$ distances for several $\mathrm{HF}, \mathrm{HCl}, \mathrm{HBr}$, and $\mathrm{HCN}$ complexes. It also lists the $r_{\mathrm{ESP}}$ for the B molecules. ${ }^{6}$ Equation (1) fits all these data and the correlation coefficients are 0.93 , 0.91, 0.89, and 0.91 for $\mathrm{HF}, \mathrm{HCl}, \mathrm{HBr}$, and $\mathrm{HCN}$, respectively. The slopes for $\mathrm{HF}, \mathrm{HCl}, \mathrm{HBr}$, and $\mathrm{HCN}$ are 1.06 , $1.06,1.22$, and 1.10 , respectively. In order to estimate a more meaningful effective size of $\mathrm{H}$ in $\mathrm{HX}\left(r_{\mathrm{Hyd}}-r_{\mathrm{ESP}}\right)$ was plotted as a function of $r_{\mathrm{ESP}}$ and Fig. 1 shows the results. The slope in this plot was forced to be zero so that the intercept could be related to the effective size of $\mathrm{H}$ in the HX. The intercepts from Fig. 1 are quite enlightening. They are 0.55 $\pm 0.07,0.74 \pm 0.08,0.80 \pm 0.11$, and $0.93 \pm 0.07 \AA$ for $\mathrm{HF}$, $\mathrm{HCl}, \mathrm{HBr}$, and $\mathrm{HCN}$, respectively. As is evident from Fig. 1, one should be able to get a reasonable estimate for intermolecular separation for B-HX just by adding $r_{\mathrm{ESP}}$ for B to the intercept for HX. These intercepts give a "H bonding radii", for HX.

The "H bond radius" of HX is increasing with the decreasing dipole moment of HX. Figure 2 shows the variation of the " $\mathrm{H}$ bond radius" as a function of the dipole moment of HX. The correlation is extremely good with a correlation coefficient of 0.99. By extrapolating to zero dipole moment, one can estimate the van der Waals radius of $H$ to be 1.00 $\pm 0.10 \AA$ which is much closer to the van der Waals radius 
TABLE I. The $r_{\mathrm{ESP}}$ values of the bases (B) and the H-bond distances ( $\left.r_{\mathrm{HYD}}\right)$ for the H-bonded complexes B-HX. All the distances are in $\AA$.

\begin{tabular}{|c|c|c|c|c|c|}
\hline \multirow[b]{2}{*}{ B } & \multirow[b]{2}{*}{$r_{\mathrm{ESP}}^{\mathrm{a}}$} & \multicolumn{4}{|c|}{$r_{\mathrm{HYD}}$ of $\mathrm{B}-\mathrm{HX}$} \\
\hline & & $\mathrm{X}=\mathrm{F}$ & $\mathrm{X}=\mathrm{Cl}$ & $\mathrm{X}=\mathrm{Br}$ & $\mathrm{X}=\mathrm{CN}$ \\
\hline $\mathrm{HF}$ & 1.27 & $1.86^{\mathrm{b}}$ & $2.08^{\mathrm{d}}$ & & \\
\hline $\mathrm{H}_{2} \mathrm{O}$ & 1.27 & $1.74^{c}$ & $1.93^{\mathrm{d}}$ & $1.99^{j}$ & $2.08^{\mathrm{m}}$ \\
\hline $\mathrm{HCN}$ & 1.36 & $1.87^{\mathrm{a}}$ & $2.13^{\mathrm{d}}$ & $2.19^{\mathrm{d}}$ & $2.24^{\mathrm{n}}$ \\
\hline $\mathrm{H}_{3} \mathrm{~N}$ & 1.25 & $1.78^{\mathrm{a}}$ & $1.85^{\mathrm{d}}$ & $1.83^{\mathrm{d}}$ & $2.16^{\mathrm{o}}$ \\
\hline $\mathrm{OC}$ & 1.54 & $2.12^{\mathrm{a}}$ & $2.41^{\mathrm{d}}$ & $2.49^{\mathrm{d}}$ & $2.61^{p}$ \\
\hline $\mathrm{C}_{2} \mathrm{H}_{2}$ & 1.60 & $2.20^{\mathrm{a}}$ & $2.42^{\mathrm{d}}$ & & $2.59^{\mathrm{q}}$ \\
\hline $\mathrm{C}_{2} \mathrm{H}_{4}$ & 1.62 & $2.22^{\mathrm{a}}$ & $2.44^{\mathrm{d}}$ & $2.49^{\mathrm{d}}$ & $2.64^{r}$ \\
\hline $\mathrm{H}_{2} \mathrm{~S}$ & 1.79 & $2.32^{\mathrm{a}}$ & $2.53^{\mathrm{d}}$ & $2.57^{\mathrm{d}}$ & $2.75^{\mathrm{s}}$ \\
\hline $\mathrm{CH}_{3} \mathrm{CN}$ & 1.34 & $1.83^{\mathrm{a}}$ & $2.01^{\mathrm{e}}$ & $2.07^{\mathrm{e}}$ & $2.21^{\mathrm{t}}$ \\
\hline $\mathrm{C}_{3} \mathrm{H}_{6}$ & 1.52 & $2.10^{\mathrm{a}}$ & $2.28^{\mathrm{d}}$ & & $2.41^{\mathrm{u}}$ \\
\hline $\mathrm{SO}_{2}$ & 1.32 & $1.89^{\mathrm{a}}$ & $2.10^{\mathrm{d}}$ & & \\
\hline $\mathrm{C}_{6} \mathrm{H}_{6}$ & 1.93 & $2.65^{\mathrm{a}}$ & $2.71^{\mathrm{d}}$ & $2.72^{\mathrm{k}}$ & $2.79^{\mathrm{v}}$ \\
\hline $\mathrm{B}_{2} \mathrm{H}_{6}$ & 2.08 & $2.50^{\mathrm{a}}$ & $2.69^{f}$ & & \\
\hline $\mathrm{CO}_{2}$ & 1.46 & $1.91^{\mathrm{a}}$ & $2.15^{\mathrm{g}}$ & & $2.35^{\mathrm{w}}$ \\
\hline $\mathrm{N}_{2} \mathrm{O}$ & 1.40 & $1.94^{\mathrm{a}}$ & $2.08^{\mathrm{h}}$ & & \\
\hline $\mathrm{H}_{2} \mathrm{CO}$ & 1.26 & $1.73^{\mathrm{a}}$ & $1.97^{\mathrm{d}}$ & & $2.21^{\mathrm{x}}$ \\
\hline $\mathrm{N}_{2}$ & 1.57 & $2.16^{\mathrm{a}}$ & $2.42^{\mathrm{i}}$ & $2.52^{1}$ & $2.55^{\mathrm{y}}$ \\
\hline
\end{tabular}

${ }^{\mathrm{a}}$ Reference 6 .

${ }^{\mathrm{b}}$ Reference 7.

${ }^{\mathrm{c}}$ Reference 8 .

${ }^{\mathrm{d}}$ Reference 5 .

eReference 9.

${ }^{\mathrm{f}}$ Reference 10 .

geference 11.

${ }^{\mathrm{h}}$ Reference 12.

${ }^{\mathrm{i}}$ Reference 13 .

${ }^{\mathrm{j}}$ Reference 14.

${ }^{\mathrm{k}}$ Reference 15.

${ }^{l}$ Reference 16.

meference 17 .

estimated by Pauling (1.2 $⿱$ ). As this corresponds to the situation of zero dipole moment, it will be a more realistic estimate of the van der Waals radius of the $\mathrm{H}$ atom.

Figure 2 predicts that for HI complexes (based on the dipole moment of $0.44 \mathrm{D}$ ) (Ref. 30) the $\mathrm{Z}-\mathrm{H}$ distance should be $r_{\mathrm{ESP}}+(0.90 \pm 0.11) \AA$. This prediction is validated by the

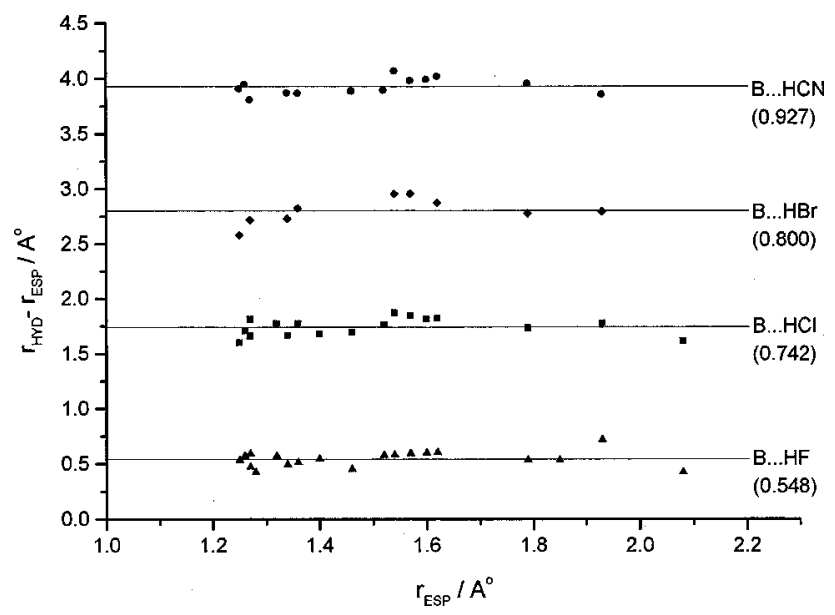

FIG. 1. Plot of $\left(r_{\mathrm{HYD}}-r_{\mathrm{ESP}}\right)$ vs $r_{\mathrm{ESP}}$ for B-HX complexes. A constant $(C)$ has been added to the $\mathrm{Y}$ values of the four complexes for clarity; $C_{\mathrm{HF}}=0$, $C_{\mathrm{HCl}}=1, C_{\mathrm{HBr}}=2$, and $C_{\mathrm{HCN}}=3$. The line through the points show the best fit assuming the slope to be zero. The intercepts are shown in parentheses.

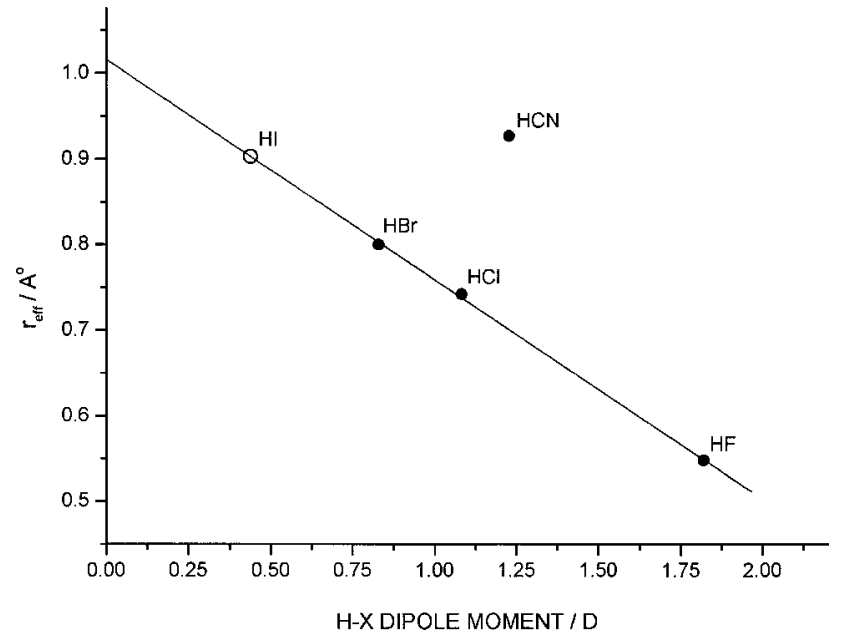

FIG. 2. Plot of the effective size of $\mathrm{H}$ in $\mathrm{HX}\left(r_{\mathrm{eff}}\right)$ vs dipole moment (Ref. 30) of $\mathrm{H}-\mathrm{X}$. The fit includes only $\mathrm{HF}, \mathrm{HCl}$, and $\mathrm{HBr}$. For $\mathrm{HCN}$, the $\mathrm{C}-\mathrm{H}$ bond moment (Ref. 4) is shown and it does not fit in the line. For HI, the predicted value for $r_{\text {eff }}$ is shown as an open circle.

limited experimental data available on $\mathrm{HI}$ complexes. The distances observed are $0.86,0.93$, and $1.11 \AA$ for the $\mathrm{H}_{2} \mathrm{O},{ }^{31}$ $\mathrm{HCN},{ }^{32}$ and OC (Ref. 33) complexes with HI. For the $\mathrm{B}-\mathrm{H}_{2}$ complexes, the $r_{\mathrm{Hyd}}$ should be closer to $(1.01 \pm 0.10)$ $+r_{\text {ESP }} \AA$. Structural data on $\mathrm{H}_{2}$ and $\mathrm{HI}$ complexes are still scarce and we hope this paper will stimulate efforts to study these complexes.

The authors thank the Department of Science and Technology, India and the Director, Indian Institute of Science for partial support and Professors A. G. Samuelson and S. R. Gadre for stimulating discussions.

${ }^{1}$ L. Pauling, The Nature of the Chemical Bond (Cornell University Press, Ithaca, 1960).

${ }^{2}$ K. Müller-Dethlefs and P. Hobza, Chem. Rev. 100, 143 (2000).

${ }^{3}$ van der Waals molecules-II, Special issue Chem. Rev. 94 (1994).

${ }^{4}$ A. D. Buckingham and P. W. Fowler, Can. J. Chem. 63, 2018 (1985).

${ }^{5}$ A. C. Legon, Angew. Chem. Int. Ed. Engl. 38, 2686 (1999), and references therein.

${ }^{6}$ S. R. Gadre and P. K. Bhadane, J. Chem. Phys. 107, 5625 (1997), and references therein.

${ }^{7}$ T. R. Dyke, B. J. Howard, and W. Klemperer, J. Chem. Phys. 56, 2442 (1972).

${ }^{8}$ J. W. Bevan, Z. Kisiel, A. C. Legon, D. J. Millen, and S. C. Rogers, Proc. R. Soc. London, Ser. A 372, 441 (1980).

${ }^{9}$ A. C. Legon, D. J. Millen, and H. M. North, J. Phys. Chem. 91, 5210 (1987).

${ }^{10}$ C. Chuang, T. D. Klots, R. S. Ruoff, T. Emilsson, and H. S. Gutowsky, J. Chem. Phys. 95, 1552 (1991).

${ }^{11}$ S. W. Sharpe, Y. P. Zeng, C. Wittig, and R. A. Beaudet, J. Chem. Phys. 92, 943 (1990).

${ }^{12}$ Y. P. Zeng, S. W. Sharpe, D. Reifschneider, C. Wittig, and R. A. Beaudet, J. Chem. Phys. 93, 183 (1990).

${ }^{13}$ R. S. Altman, M. D. Marshall, and W. Klemperer, J. Chem. Phys. 79, 57 (1983).

${ }^{14}$ A. C. Legon and A. P. Suckley, Chem. Phys. Lett. 150, 153 (1988).

${ }^{15}$ S. A. Cooke, G. K. Corlett, C. M. Evans, and A. C. Legon, Chem. Phys. Lett. 272, 61 (1997).

${ }^{16}$ N. W. Howard and A. C. Legon, J. Chem. Phys. 90, 672 (1989).

${ }^{17}$ A. J. Fillery, A. C. Legon, and L. C. Willoughby, Chem. Phys. Lett. 98, 369 (1983).

${ }^{18}$ K. Georgiou, A. C. Legon, D. J. Millen, and P. J. Mjoberg, Proc. R. Soc. London, Ser. A 399, 377 (1985). 
${ }^{19}$ G. T. Fraser, K. R. Leopold, D. D. Nelson, A. Tung, and W. Klemperer, J. Chem. Phys. 80, 3073 (1984).

${ }^{20}$ E. J. Goodwin and A. C. Legon, Chem. Phys. 87, 81 (1984).

${ }^{21}$ P. D. Aldrich, S. G. Kukolich, and E. J. Campbell, J. Chem. Phys. 78, 3521 (1983).

${ }^{22}$ S. G. Kukolich, W. G. Read, and P. D. Aldrich, J. Chem. Phys. 78, 3552 (1983).

${ }^{23}$ E. J. Goodwin and A. C. Legon, J. Chem. Soc., Faraday Trans. 2 80, 1669 (1984).

${ }^{24}$ N. W. Howard and A. C. Legon, J. Chem. Soc., Faraday Trans. 2 83, 991 (1987).

${ }^{25}$ S. G. Kukolich, J. Chem. Phys. 78, 4832 (1983).
${ }^{26}$ H. S. Gutowsky, E. Arunan, T. Emilsson, S. L. Tschopp, and C. E. Dykstra, J. Chem. Phys. 103, 3917 (1995).

${ }^{27}$ T. D. Klots, R. S. Ruoff, and H. S. Gutowsky, J. Chem. Phys. 90, 4216 (1989).

${ }^{28}$ E. J. Goodwin and A. C. Legon, J. Chem. Phys. 87, 2426 (1987).

${ }^{29}$ E. J. Goodwin and A. C. Legon, J. Chem. Phys. 82, 4434 (1985).

${ }^{30}$ Handbook of Chemistry and Physics, 80th ed. (CRC Press, Boca Raton, 1999-2000).

${ }^{31}$ A. McIntosh, T. Walther, R. R. Lucchese, J. W. Bevan, R. D. Suenram, and A. C. Legon, Chem. Phys. Lett. 314, 57 (1999).

${ }^{32}$ P. W. Fowler and A. C. Legon, Chem. Phys. Lett. 226, 501 (1994).

${ }^{33}$ Z. Wang, R. R. Lucchese, J. W. Bevan, A. P. Suckley, C. A. Rego, and A. C. Legon, J. Chem. Phys. 98, 1761 (1993). 